\title{
Study of Cutting and Labeling of Polymethylmethacrylate Using a CO2 Laser
}

\author{
Dolchinkov Nikolay Todorov \\ National Military University ,, Vasil \\ Levski“", Veliko Tarnovo, Bulgaria \\ National Research University "Moscow \\ Power Engineering Institute”, Moscow, \\ Russia \\ Veliko Tarnovo, Bulgaria \\ n_dolchinkov@abv.bg \\ Nedyalkov Deyan Dimitrov \\ National Military University ,, Vasil \\ Levski“",Veliko Tarnovo, Bulgaria \\ Veliko Tarnovo, Bulgaria \\ ddned@abv.bg
}

\author{
Lazov Lyubomir \\ Rezekne Academy of Technologies, \\ Faculty of Engineering) \\ Address: Atbrivosanas aleja 115,) \\ Rezekne, LV-4601, Latvia \\ 1lazov@abv.bg
}

Linkov Lyubomir Ivanov

National Military University ,,Vasil

Levski“, Veliko Tarnovo, Bulgaria

Veliko Tarnovo, Bulgaria

kubratovec@gmail.com

\author{
Ivanov Jordan Shterev \\ National Military University ,, Vasil \\ Levski", Veliko Tarnovo, Bulgaria \\ Veliko Tarnovo, Bulgaria \\ jshterev@abv.bg
}

\begin{abstract}
Progress in direct laser marking when processing plastics with unmatched quality of markings, contrast and speed. This article presents the latest generation of laser materials and laser equipment systems. When properly applied, laser marking can provide quality for production and add value to the appearance and function of the product.

Describe the parameters influencing the depth of the laser marking of polymethylmethacrylate (PMMA) products. Experimental results are presented for determining the quality of cuts on the polymer surface at specific parameters - power and speed.
\end{abstract}

Keywords - cutting, laser, marking, pleksiglas, research. I. INTRODUCTION

Polymethyl methacrylate, widely known under the trade name Plexiglas, is a synthetic thermoplastic transparent polymer. It is also found under the trademarks lemacryl, perpsex, plastid, acrylate, acrylate, acrylate, etc., also called organic glass, acrylic glass or acrylic (fig. 1) $[14]$.

It was created in 1928 and was sold in 1933 by Rohm and Haas Company [15].

Plexiglas is used as an alternative to glass. It has the following properties:

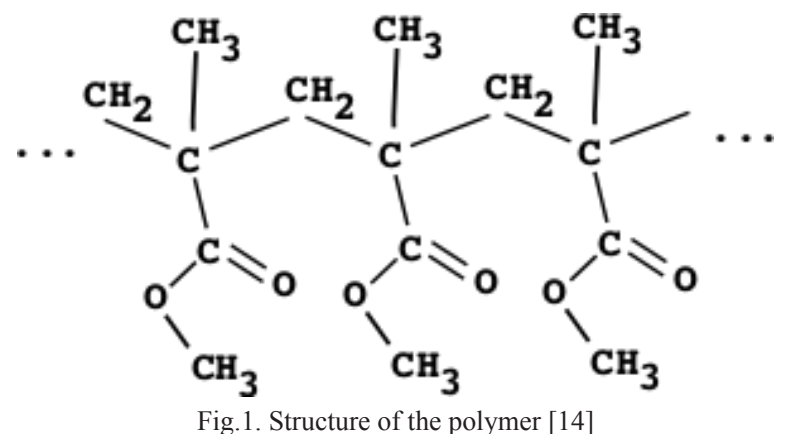

lighter: its density $(1190 \mathrm{~kg} / \mathrm{m} 3)$ is approximately twice as low as that of the glass;

resistant to external influences (humidity, cold, etc.);

softer than the glass and therefore more scratchsensitive;

when heated above $100^{\circ} \mathrm{C}$ becomes plastic and lends itself to molding;

it is easily processed with metal cutting and woodworking machines and tools;

perfectly cut and engraved with a laser;

passes ultraviolet rays and X-rays, but filters infrared rays; passes less light (92-93\% vs. 99\%) from the glass [9]; 14].

is not resistant to the effects of organic solvents [1,

Deliberating upon the question which innovation changed the world, many scientists would answer that it was the laser. Soon after its invention in 1960 it attracted the attention of many scientists from all over the world $[6,12]$.

Laser sources emit radiations with wavelengths in a wide spectral range - from ultraviolet, visible and infrared to continuous and pulsed modes. Some of the laser technologies are: laser marking, cutting, engraving, welding, drilling of holes and many others [2].

Laser devices are the core technology in instruments performing vital functions in many industries including transportation, healthcare, and telecommunications [4]. Laser marking and laser cutting technology are now widely associated with plastics.

The most common mechanism of surface reaction is thermal chemical "carbonization" or "charring". First, the charging process occurs when the absorbed energy increases the local temperature of the material around the subject of absorption, high enough to cause thermal decomposition of the polymer [13]. While this may lead to burning of the polymer in the presence of oxygen, the limited supply of oxygen inside the substrate results in polymerization of the polymer to produce a black or dark

Print ISSN 1691-5402

Online ISSN 2256-070X

http://dx.doi.org/10.17770/etr2019vol3.4203

(C) 2019 Dolchinkov Nikolay Todorov, Lazov Lyubomir, Ivanov Jordan Shterev, Nedyalkov Deyan Dimitrov,

Linkov Lyubomir Ivanov.

Published by Rezekne Academy of Technologies.

This is an open access article under the Creative Commons Attribution 4.0 International License. 
contrast to light.

The aim of the experiments at the Technological Academy Resets, on the basis of analyzing the parameters (velocity and power) change, is to improve the marking and cutting of polymethylmethacrylate (PMMA) products, to obtain data that would be useful in optimizing the production lines using laser technologies for processing PMMA. The studies conducted show the application of laser marking and cutting. The optimal parameters of the laser device were found to perform a $9.5 \mathrm{~mm}$ thick PMMA quality cut. At the same time, results were obtained for making markings by removing a certain volume of material.

\section{EQUIPMENT AND EXPERIMENTAL ES- TABLISHMENT}

The wavelength (energy) is important. The materials have to absorb the laser energy if a good marking effect is to occur. The more plastic materials are able to absorb the laser energy at a wavelength of $1064 \mathrm{~nm}$ (which is the infrared band - Nd:YAG). Here is used CO2, which is important because of different wavelength and the results.

Gas laser CHANXAN CW 1325 CO2 active, 1-150 watts power, 1-400 mm / s, laser beam wavelength 10.6 $\mathrm{mm}$, maximum marking area: $2500 \times 1300 \mathrm{~mm}$, maximum laser size focal spot is $100 \mathrm{~mm}$ and water cooling system was used.

The surface power density SPD of the laser beam is determined by:

$$
S P D=\frac{P}{S}
$$

where $\mathrm{P}$ is the power of laser beam and $\mathrm{S}$ is the area of the laser beam section in focus. Laser control was performed using the RdWorks software [7,10].

In relation to the influence of the laser beam on the plastic, the linear energy density LED of the laser [8] beam is defined on a unit length depending on the velocity:

$$
L E D=\frac{P}{v}
$$

where $P$ is the power of laser beam and $v$ is the speed of laser beam movement on the plastic [11].

The focusing system controls the laser beam spot direction is important system part. The area diameter of the focused laser beam defined marking line width and the real marking efficiency and the penetrating depth of the laser beam. The diameter depends of the lens focal length and the of the laser beam deviation.

Polymethylmethacrylate (PMMA) is a transparent thermoplastic material that is light and stable. As a multifunctional material used in a wide range of applications. The thickness of the plexiglass used is 10 $\mathrm{mm}$.

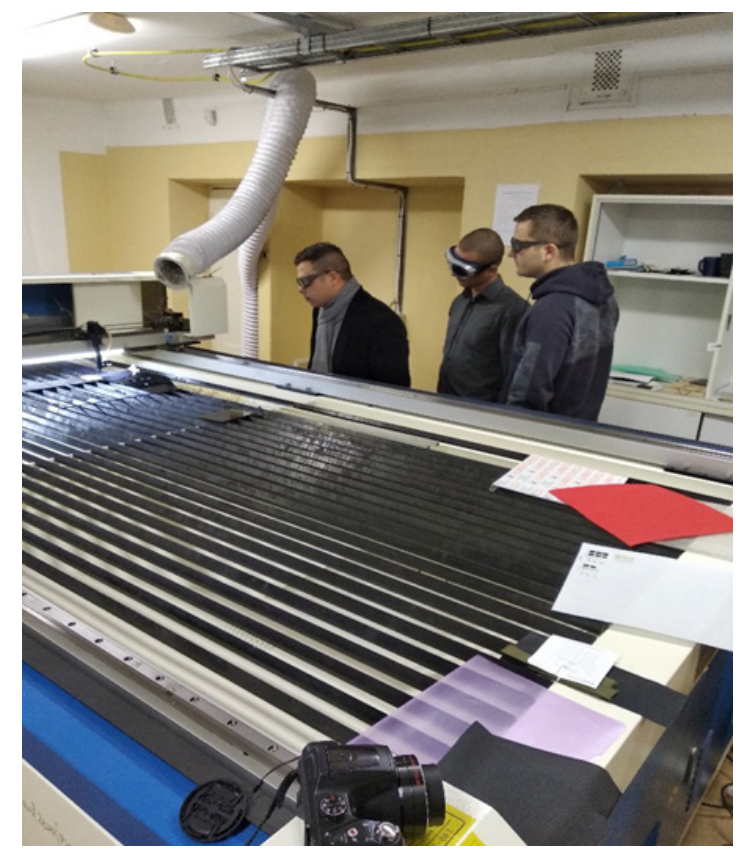

Fig.2. The laser used for the experiments

Fig. 2 This figure is an image of the laser used during our experiment. Marking and cutting of the plexiglass was done at the laser center of the Rezekne Technological Academy

Experimental data were obtained using a Dino-lite AM4515ZTL digital microscope having the following 1.3 MPx result, 10-140X magnification and polarization (fig. 3).

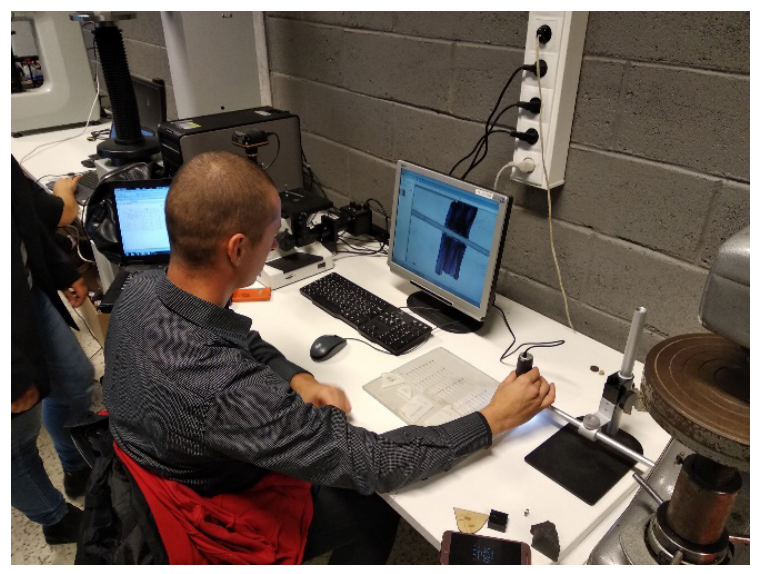

Fig 3. Operating the electronic microscope

We investigate the possibility of marking and cutting the $\mathrm{CO}_{2}$ laser material. For this purpose, an experimental methodology was developed, which concludes in the following:

- A matrix of 50 lines was created. Speed and power range in the range of $10-50$ watts and $5-30 \mathrm{~mm} / \mathrm{s}$. The scheme of the matrix is shown in Fig. 4.

The main factors that influence the contrast of laser marking are $[3,4,5,6]$ : 


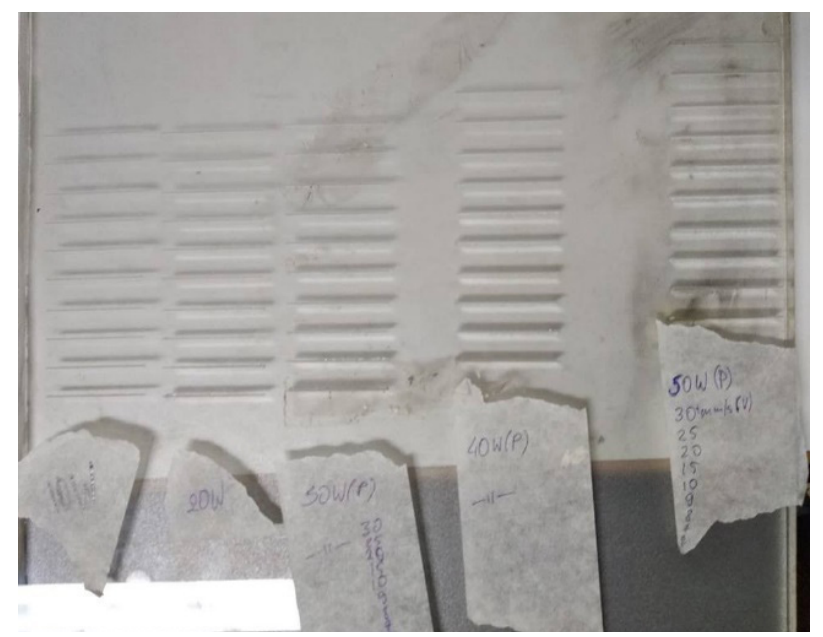

Fig. 4. Matrix

Each processing area is implemented by the raster scan method. The line-to-line step is $0.1 \mathrm{~mm}$.

Processing areas and processing quality were analyzed with the help of a digital microscope AM4515ZTL Total 50 processing areas were analyzed.

\section{LASER CutTing}

Effective cutting depth at power, $\mathrm{mm}$

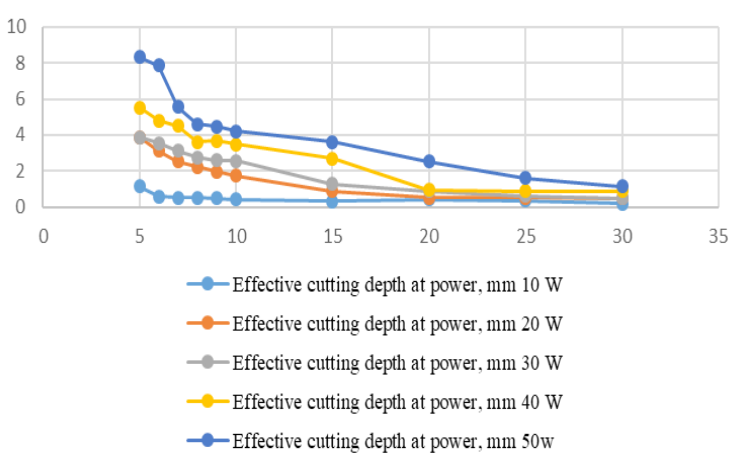

Fig 5: Effective cutting depth at power

The experimental data obtained at the laser beam power at $10 \mathrm{w}$ are shown in figure 5 . In which the width of the hole in the material is shown, the heat-affected zone (COP), the Line Energy Density (LED), and the Effective Shear Depth (ESD).

Power density is a function of the focused laser size (laser power per unit area, $\mathrm{W} / \mathrm{cm}^{2}$ ). This is different from the raw output power of the laser. Focused laser beam size for each focal length lens and laser wavelength is a function of laser beam bias controlled by the laser configuration, the size of the aperture for mode selection, and the magnification of the expansion beam (collimator beam expander).

Frequency of repetition of pulses (by acoustic-optical Q switch) and peak power density are critical parameters in forming the markings and achieving optimal contrast and velocity. High peak power at low frequency rapidly increases surface temperature, evaporates material while minimizing heat in the substrate. As the pulse repetition increases, lower peak power results in minimal evaporation, but generates more heat. The beam speed (the laser beam speed through the work surface) is also a critical factor.
Table 2 gives the optimal laser marking parameters.

Good marking of the material (nearly $50 \%$ ) is obtained with the following technological parameters: power 10$20-30$ watts at a speed of $25-30 \mathrm{~mm} / \mathrm{s}$

Good marking through the material is obtained with the following technological parameters: power $10 \mathrm{~W} 20 \mathrm{~W}$ $30 \mathrm{~W} 40 \mathrm{~W}$ at a speed of $30-10 \mathrm{~mm} / \mathrm{s}$.

TABLE 2

OPTIMAL LASER MARKING PARAMETERS

\begin{tabular}{|c|c|c|c|c|}
\hline $\begin{array}{c}\text { Speed, } \\
\mathbf{m m} / \mathbf{s}\end{array}$ & $\begin{array}{c}\text { Width, } \\
\mathbf{m m}\end{array}$ & $\begin{array}{c}\text { COP, } \\
\mathbf{m m}\end{array}$ & $\begin{array}{c}\text { LED, } \\
\mathbf{m m}\end{array}$ & $\begin{array}{c}\text { ESD, } \\
\mathbf{~} \mathbf{m}\end{array}$ \\
\hline 5 & 0,675 & 0.029 & 2,000 & 1,145 \\
\hline 6 & 0,653 & 0.029 & 1,667 & 0,579 \\
\hline 7 & 0,576 & 0.30 & 1,429 & 0,525 \\
\hline 8 & 0,561 & 0.029 & 1,250 & 0,767 \\
\hline 9 & 0,543 & 0.029 & 1,111 & 0,512 \\
\hline 10 & 0,535 & 0.046 & 1,000 & 0,417 \\
\hline 15 & 0,511 & 0.045 & 0,667 & 0,338 \\
\hline 20 & 0,514 & 0.046 & 0,500 & 0,406 \\
\hline 25 & 0,478 & 0.054 & 0,400 & 0,350 \\
\hline 30 & 0,448 & 0.055 & 0,333 & 0,188 \\
\hline
\end{tabular}

Figure 5 shows a qualitative marking of the material at a power of $20 \mathrm{w}$ and a speed of $25 \mathrm{~mm} / \mathrm{s}$.

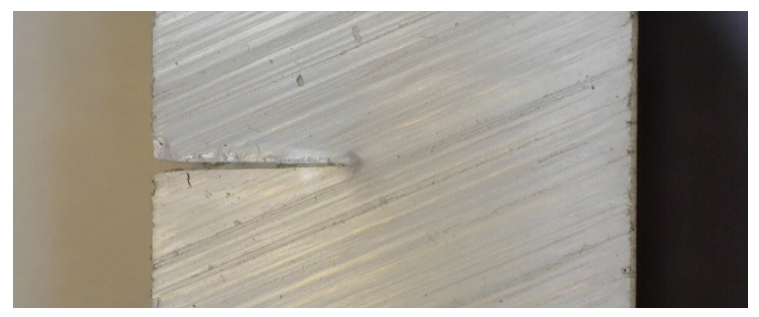

Fig.5. qualitative marking of the material at a power of $20 \mathrm{w}$ and a speed of $25 \mathrm{~mm} / \mathrm{s}$.

Figure 6 shows a quality cut of the material at a power of $50 \mathrm{w}$ and a speed of $5 \mathrm{~mm} / \mathrm{s}$. Figure 7 shows the threshold of destruction,

Each processing area (line) is implemented by the raster scan method. The line-to-line step is $0.1 \mathrm{~mm}$. In Fig. the processing area and the parameters for each zone are shown.

Qualitative shear of the material results in the following parameters constant power $50 \mathrm{~W}$ and $40 \mathrm{~W}$ and velocity ranging from $5-7 \mathrm{~mm} / \mathrm{s}$. In the first zone, the LPE is; in the second zone and in the third zone is $0.13 \mathrm{~J} / \mathrm{mm}$.

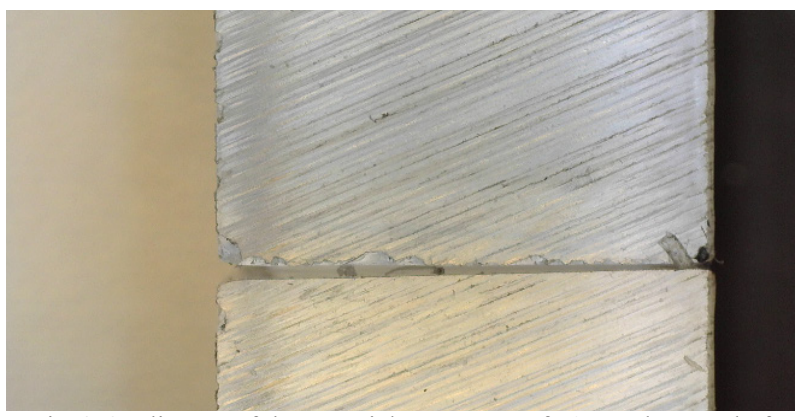

Fig.6. Quality cut of the material at a power of $50 \mathrm{w}$ and a speed of $5 \mathrm{~mm} / \mathrm{s}$ 


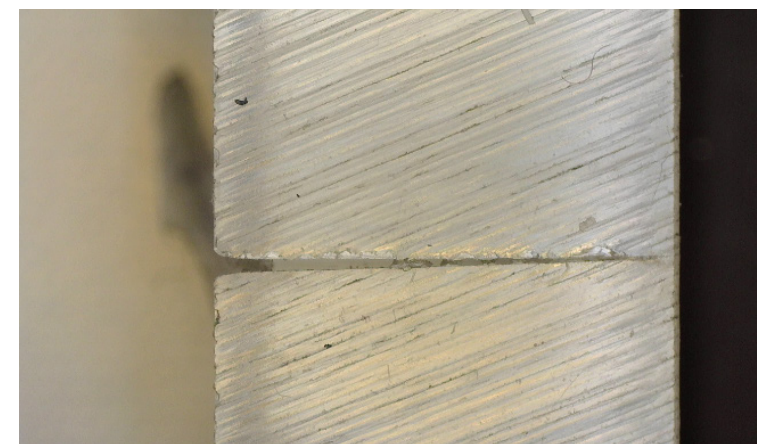

Fig.7. The threshold of destruction

\section{CONCLUSION}

From the conducted study and the analyzed experimental data, the following conclusions can be drawn:

1. Quality cut of the material is achieved with the following parameters: for white and red felt permanent power $50 \mathrm{~W}$ and $40 \mathrm{~W}$ and speed ranging from $5-7 \mathrm{~mm} / \mathrm{s}$. In the first zone, the LPE is; in the second zone and in the third zone is $0.13 \mathrm{~J} / \mathrm{mm}$.

2. Good marking by lightening of the material is obtained with the following technological parameters

Power $10-20-30-40$ at a speed of $30-10 \mathrm{~mm} / \mathrm{s}$.

3. For laser cutting of plexiglass, best cut parameters are obtained at a power of 40 - 50 watts and a speed of $5-7 \mathrm{~mm} / \mathrm{s}$. When power is increased, the cut-off line is better outlined without residual unevenness, but this will lead to unnecessary energy consumption and no practical value. When the thickness of the material is reduced, less laser power is required to obtain a full cut.

4. Low power cuts of the laser beam result in incomplete shearing. We then see a mark on a certain depth of the material depending on the applied power. From our research we can select laser power and speed to obtain a mark of different depth depending on the desired depth of engraving or marking.

5. The $9.5 \mathrm{~mm}$ thick Plexiglas test material is suitable for laser marking and engraving. It is convenient for laser cutting with medium power lasers and good shear quality. It can be used to make billboards, souvenirs and others that can be used in both military and civilian industries.

6 . The results obtained can serve as a basis for further studies with similar materials, and the data obtained can be used practically when working with the $\mathrm{CO}_{2}$ laser materials tested. This study can be continued using materials of a similar structure and finding the best ingredient of the Plexiglas for performing qualitative marking.

\section{REFERENCES}

[1] Angelova Y., Lazov L., Mezinska S., Rezene, Latvia, Innovative Laser Technology in Textile Industry: Marking and Engraving, Technical University of Gabrovo, Bulgaria, Rezekne Academy of Technologies, Faculty of Engineering, Rezekne, Latvia Proceedings of the 11th International Scientific and Practical Conference. Volume III, 15-21.

[2] Grigiryants A., I. Shiganov, A. Misyurov. Technological processes of laser processing, ed. MGTU them. N. Bauman, Moscow, 2006

[3] Dolchinkov N., Shterev Y., St. Lilianova, D. Boganova, M. Peneva, L. Linkov, D. Nedialkov, Exploring the possibility of laser cutting with $\mathrm{CO} 2$ laser on felt in the range from $1 \mathrm{~W}$ to $26 \mathrm{~W}$ power, International scientific journal: Industry 4.0 Issue 1/2019, ISBN 2534-8582, стр. 29-31.

[4] Eichler, J., L. Dünkel, Eppich Die Strahlqualität von Lasern Wie bestimmt man Beugungsmaßzahl und Strahldurchmesser in der Praxis?, Laser Technik Journal 1 (2004), Nr. 2

[5] Lazov L.., Angelov N., The 50th anniversary of laser, Technical University of Gabrovo, Bulgaria, 2010.

[6] Lazov L., E. Teirumnieks, Application of laser technology in the army, Proceedings of International Scientific Conference "Defense Technologies", Faculty of Artillery, Air Defense and Communication and Information Systems, Shumen, Bulgaria, 2018

[7] Lazov L, H. Deneva, E. Teirumnieka, Study of Auxiliary Gas Pressure on Laser Cutting Technology, Environment. Technology. Resources, Rezekne, Latvia Proceedings of the 11th International Scientific and Practical Conference. Volume III, 159-162

[8] Lazov L.., Angelov N. Optimization of laser marking with the help of simulation models, International Scientific Conference, Gabrovo, 2010.

[9] Lazov L., Angelov N., Scanning the contrast in function of velocity in laser marking of samples of steel, International Scientific Conference, Gabrovo, 2010.

[10] Petrov N., Optimization of the marking process with laser radiation of samples of tool steel, dissertation, Gabrovo, 2011.

[11] Shterev Y., N. Dolchinkov, St. Lilianova, D. Boganova, M. Peneva, L. Linkov, D. Nedialkov, Laser marking and cutting of plexiglas with $\mathrm{CO}_{2}$, International journal for science Machines, Technologies, Materials 4/2018 стр 494-496.

[12] https://www.laserfelt.com/

[13] http://chris-reilly.org/blog/how-to-laser-cut-felt/

[14] http://digitalcommons.unl.edu/tsaconf/index.2.html

[15] https://bg.wikipedia.org/wiki/Полиметилметакрилат

*Note: This article is presented with the assistance of project BG05M2OP001-2.009-0001, Support for the development of human resources and the research potential of the National Military University "Vasil Levski" for its assertion as a modern knowledge center. 